\title{
MOTIVATIONAL SEGMENTATION OF THE GASTRONOMIC TOURIST IN THE CITY OF CÓRDOBA (SPAIN)
}

\author{
Javier JIMÉNEZ-BELTRÁN \\ University of Cordoba, Faculty of Law and Business and Economic Sciences, Department \\ of Applied Economics; c/ Puerta Nueva s/n 14002 Cordoba, Spain, e-mail: fjbeltran@uco.es
}

\section{Carol JARA-ALBA}

Casa Grande University, Department of Research, Guayaquil 090613, Ecuador, e-mail: cjara@casagrande.edu.ec

\section{Jaime ROLDAN NOGUERAS}

University of Cordoba, Faculty of Law and Business and Economic Sciences, Department of Applied Economics; c/ Puerta Nueva s/n 14002 Cordoba, Spain, e-mail: dt1ronoj@uco.es

\section{Gema GOMEZ-CASERO*}

University of Cordoba, Faculty of Law and Business and Economic Sciences, Department of Applied Economics; c/ Puerta Nueva s/n 14002 Cordoba, Spain, e-mail: ggomezfuentes@uco.es

\begin{abstract}
Citation: Jiménez-Beltrán, J., Jara-Alba, C., Roldán Nogueras, J., \& Gomez-Casero, G. (2018). MOTIVATIONAL SEGMENTATION OF THE GASTRONOMIC TOURIST IN THE CITY OF CÓRDOBA (SPAIN). GeoJournal of Tourism and Geosites, 26(3), 874-886. https://doi.org/10.30892/gtg.26316-404

Abstract: The objective is to analyze the motivations of tourists who visit a city with a rich cultural heritage, both architectural and culinary. Based on these motivations, segmentation is carried out. Regarding the methodology, after a factorial analysis and taking the extracted motivational dimensions as reference, the multivariate technique of grouping the cases was used, obtaining four clusters. Findings show that tourists of Córdoba are attracted to gastronomic features in addition to architectural heritage, together forming a cultural product that is highly valued. The article also analyzes neophilia and neophobia.
\end{abstract}

Key words: gastronomy, motivation, neophobia, neophilia, tourism segmentation, gastronomic tourism, food tourism.

\section{INTRODUCTION}

When tourists travel they do not want to experience only what they have already seen or read. The new tourist seeks experiences and unique and particular aspects of the destination; the tourist is not only interested in knowing the tangible heritage but also wants to live it and deepen the knowledge of the other elements that make up the place

\footnotetext{
* Corresponding author
} 
(López-Guzmán et al., 2019). According to Matlovičová, Kolesárová \& Matlovič (2014), culinary tourism can be considered also tours where the activities associated with food tasting are of the secondary importance. Following Madaleno et al. (2016), tourism evolves from the classic contemplation of physical places towards more experiential activities where it is possible to discover, participate, and learn from the place. Specifically, cultural tourism today is not just about maximizing assets of a tangible nature (visiting museums, historical sites, or art galleries). It also includes, for example, knowledge of the dishes and gastronomy that characterize a region (Huang, 2017).

This fact is relevant because through culinary practice it is possible to know the culture of a destination in a close and participatory way, far from the contemplative perspective that has traditionally characterized cultural tourism. In this context, the tourist interested in gastronomy investigates new products and forms that respond to the tourist's tastes, since the motivations to visit a destination are constantly evolving (Lin \& Chen, 2014). In this way, the objective of this study is to analyse the motivations of tourists who come to a city with a rich cultural heritage, not only from an architectural point of view but also a culinary one. Based on this analysis, the study will carry out a segmentation. In addition, personality traits will be analysed. To achieve this goal, the article is structured as follows. The next section provides a review of the literature, followed by the methodology, the results of the investigation, and conclusions.

\section{LITERATURE REVIEW}

Following Björk and Kauppinen-Räisänen (2016), there are three types of tourists in relation to gastronomy and gastronomic motivations. First there are those who travel with the sole purpose of experiencing the gastronomy (including drinking) of a destination. They have a real interest in the culinary experience, and this works as a trigger for the choice of destination. Then there are those who perceive the gastronomic experience as something important and offering an exclusive experience, but not an essential one, for the choice of the visited destination. In terms of motivation, the gastronomic experience is combined with the cultural experience of a destination for the pursuit of personal enrichment (Kim \& Kim, 2017). For example, tourists might take a trip to discover the architectural heritage of a destination while tasting the typical cuisine as part of the experience (Akdag et al., 2018). Third are those tourists who approach the gastronomy in a destination only to the extent that it represents a physical need to satisfy. For them, gastronomy is part of the daily practices of any tourist in the place of visit, since it is a basic physiological requirement (Lin \& Chen, 2014; Chen \& Huang, 2018).

However, we must not forget that although eating is a daily and common activity, experiencing moments of satisfaction is important for the tourist experience, so local gastronomy can be key to that objective, although it does not represent an initial motivation (Oh et al., 2018). Although local gastronomy is not the only reason for choosing a destination (Privitera, et al., 2018), there is a segment of tourists who want to deepen their knowledge and enjoy their tasting (while relaxing). According to different researchers (Yusuf, 2017; López-Guzmán et al., 2017, 2018), these tourists must also be considered gastronomic. Therefore, the present investigation considers relevant the adoption of the terminology provided by the World Tourism Organization (WTO, 2012) to designate gastronomic tourists who plan their trips, partially or totally, to taste and/or participate in activities related to the ingredients and dishes of a destination.

\section{The gastronomic motivation}

The tasting of specialties is, on certain occasions, the main attraction to visit a destination (Wang \& Mattila, 2015). In the analysis of tourism motivations, one of the 
most accepted classifications is based on the push-pull theory (Crompton, 1979; Anton et al., 2017). Anton et al. (2017) considered that the existence of internal motivations (push) shows a connection with individuals' emotions and corresponds to their desires and stimuli, along with the wish for escape, relaxation, rest, novelty, and having a cultural experience. The external reasons (pull) are related to the attractiveness of the destination, which includes tangible resources such as historical, cultural, natural, or culinary heritage. In essence, push motivations induce individuals to make the trip, while pull factors relate to the appeal of the destination, motivating them to travel to it once the decision has been made. Culinary heritage has both roles: individuals are pushed beyond the ingredients and dishes that are known and familiar, and at the same time they are pulled to experience novel and exciting tastes (Fields, 2002).

As indicated above, local gastronomy plays a fundamental role in the choice of destination (Fields, 2002; Son \& Xu, 2013). Following Fields (2002), four dimensions influence tourists' motivation to approach the local culinary heritage: physical (the pleasure of tasting an essential dish); cultural (the possibility of knowing a place through its products and typical dishes); interpersonal (a pleasant lunch with company is pleasant and relaxing, and allows socialization); and status and prestige (visiting a restaurant of recognized value is associated with having a certain economic and social level). Based on these categories, Kim et al. (2009) developed nine dimensions that, in their opinion, intervene in the composition of a culinary motivational model: acquisition of knowledge, authentic experience, union, prestige, exciting experience, escape from routine, sensory attraction, concern for health, and physical environment. After the investigation by Kim et al. (2009), a new scale of motivation was developed, which reduced the initial nine components to five (cultural experience, interpersonal relationship, emotion, sensory appeal, and healthy attractiveness) to integrate a local gastronomic tasting model (Dimitrovski \& Crespi-Vallbona, 2016; Maeng et al., 2016). Then each of the dimensions was developed, as well as the contributions that took place. First, cultural experience results from integrating knowledge acquisition and authentic experience. The acquisition of knowledge is oriented to the need to share the local culinary culture as an opportunity to learn about a different culture, while connecting with the intangible heritage of the destination (Björk \& Kauppinen-Räisänen, 2016).

Secondly, the motivation of interpersonal relationship incorporates union and prestige. A tourist destination can be a meeting place that provides a unique opportunity for family members and other traveling companions with similar interests (Xu \& Zhang, 2016). In this context, the tasting of local specialties is recognized as a collection of social practices that allow tourists to interact (Kim et al., 2013; Sthapit, 2017). For example, a lunch on a holiday contains a social function that includes the construction of new ties while reinforcing existing ones (Goolaup \& Mossberg, 2017). Third, the approach to local gastronomy is accepted as a way of escaping from the routine at the same time that it is an exciting experience, both united under the factor of emotion (Tanford \& Jung, 2017). Sometimes it is fundamental to distance oneself from everyday reality as an effective tool to avoid the repetitive aspects that life offers (Kim et al., 2013). Thus, the incursion into local markets and typical culinary establishments, normally different from those visited regularly, allows us to take perspective and also to experience unique sensations (Sthapit et al., 2017) since the affective responses (disappointment, joy, surprise, etc.) are evoked during the course of gastronomic experiences (Yusuf, 2017).

Fourth, the dimension of sensory appeal is defined by the need to experience, through touch, smell, visual appearance, or taste, the diversity associated with the gastronomic heritage (Björk \& Kauppinen-Raisanen, 2016). Here the visual images of the 
ingredients and dishes, along with the preparation, play a preponderant role in the attraction and pleasantness (Hanks et al., 2016), which establishes culinary preferences based on the nuanced sensory experience (Ting et al., 2017; Yusuf, 2017). Finally, the healthy dimension is included because, among the characteristics that are recognized under quality culinary heritage, the presence of ingredients and local dishes stands out, resulting in their tasting as a means to improve mental or physical well-being (Kim et al., 2009; Kim \& Eves, 2014; Madaleno et al., 2016; Choe \& Kim, 2018). Kim et al. (2009) found that women and older people (with higher educational levels) showed greater concern for their health and had a greater desire to experience the local culture through tasting. Table 1 shows the evolution of the motivational dimensions (from nine to five).

Table 1. Grouping of motivational dimensions

\begin{tabular}{|c|c|c|}
\hline \multicolumn{3}{|c|}{ LOCAL GASTRONOMIC MOTIVATION DIMENSIONS } \\
\hline Kim et al., 2012 & Kim et al., 2009 & Scientific studies (year) \\
\hline \multirow{2}{*}{$\begin{array}{l}\text { Cultural } \\
\text { experience }\end{array}$} & $\begin{array}{l}\text { Acquisition of } \\
\text { knowledge }\end{array}$ & \multirow{2}{*}{$\begin{array}{l}\text { Mynttinen et al., 2015; Björk and Kauppinen-Räisänen } \\
\text { 2016; Sthapit 2017; Özdemir and Seyitoğlu } 2017\end{array}$} \\
\hline & Authentic experience & \\
\hline \multirow{2}{*}{$\begin{array}{l}\text { Interpersonal } \\
\text { relationship }\end{array}$} & Union & \multirow{2}{*}{$\begin{array}{c}\text { Kim et al., 2013; Mynttinen et al., 2015; } \\
\text { Xu and Zhang 2016; Tanford and Jung 2017; } \\
\text { Sthapit 2017; Goolaup and Mossberg 2017 }\end{array}$} \\
\hline & Prestige & \\
\hline \multirow{2}{*}{ Emotion } & Exciting experience & \multirow{2}{*}{ Björk and Kauppinen-Räisänen 2016} \\
\hline & Escape the routine & \\
\hline $\begin{array}{l}\text { Sensory } \\
\text { attraction }\end{array}$ & Sensory attraction & $\begin{array}{l}\text { Ting et al., 2017; Yusuf 2017; } \\
\text { Björk and Kauppinen-Räisänen } 2017\end{array}$ \\
\hline Healthy & Concern for health & $\begin{array}{l}\text { Seo and Yun 2015; Wang and Mattila 2015; } \\
\text { Wu et al., 2016; Madaleno et al., } 2018\end{array}$ \\
\hline
\end{tabular}

In accordance with the review of the literature, the hypotheses are the following:

$\mathrm{H}_{1}$ : Motivations related to the cuisine of a destination, in this case the city of Córdoba, are heterogeneous (Kim et al., 2013; Dimitrovski \& Crespi-Vallbona, 2016; Maeng et al., 2016). $\mathrm{H}_{2}$ : Tourists can be classified according to their interest in gastronomy (Matlovičová \& Pompura, 2013; Björk \& Kauppinen-Räisänen, 2016; López Guzmán et al., 2017, 2018; Privitera et al., 2018).

\section{Traits associated with the gastronomic personality}

In general, the tasting of specialties in a destination is characterized by its essentiality (tourists need to feed themselves), temporal scope (the stay is limited in duration), symbolic character (which can motivate the approach to a destination), and in many cases novel scenario in terms of ingredients and customs (Mak et al. 2013; Ting et al. 2017). This aspect is essential in terms of the reaction (positive or negative) that the tourist may have to a culinary heritage that, in addition to being far away, may generate suspicion or fear (Kim et al., 2010; Mynttinen et al. 2015). Recent research has confirmed how the personality traits of the individual affect the intentions of tasting local cuisine in different parts of Asia, including Hong Kong (Mak et al., 2017), Macao (Ji et al., 2016), Antalya (Caber et al., 2018), and Taiwan (Hsu et al., 2018).

\section{Personality trait: neophobia}

Neophobia, related to the behaviour of the tourist before the gastronomic choice, is based fundamentally on a tendency to avoid or restrict the choices of new flavours and local textures that sometimes have an uncertain origin (Sthapit, 2017). This is not an isolated event, and it has importance in the field of tourism, affecting the development of the culinary heritage and, by extension, the local economy of the destination (Kim et al., 2010; 
Wu et al., 2016). Therefore, three aspects stand out. In the first place, the cultural aspect is decisive, especially when the visit happens abroad, exerting great influence on tourists' perceptions and valuations. Of particular importance are flavours, ways of cooking, and learning new techniques or table manners (Kim et al., 2013; Choe \& Kim, 2018). How gastronomy is codified into acceptable or unacceptable, within a particular social group, depends on beliefs and values (Mak et al., 2017; Muhammad et al., 2016). Thus, what is understood as acceptable in one culture can be harmful and negative in another. For example, there are tourists who are upset by the presence of aquariums installed in Asian restaurants (essentially China, Hong Kong, and Korea), displaying various species of fish that will be slaughtered and prepared according to the preferences of the diners (Cohen \& Avieli, 2004). Another example is internal organs, which in many destinations are unacceptable and in others are valued positively in regard to taste, nutrition, and health. One's affective response to a destination in comparison with one's own culture is also important; for example, Westerners often choose exotic destinations perceived as mysterious and at times dangerous (Cohen \& Avieli, 2004; Madaleno et al., 2018).

Second, prior contact and familiarity with the local culinary heritage contribute to reducing the neophobic traits of tourists (Seo et al., 2013; Frisvoll et al., 2016). The proximity or knowledge of ingredients and dishes is a good predictor of taste assessment (Jang \& Kim, 2015); neophobes tend to avoid things when they are unknown (Björk \& Kauppinen-Räisänen, 2016). Therefore, food purveyors must follow different strategies: opt for visibility by providing stands or displays of the specialties available in the restaurant, or provide free samples, which may motivate the consumer to make a purchase. In both cases, the tourist becomes familiar and has an increased probability of tasting (Mak et al., 2012; Özdemir \& Seyitoğlu, 2017). For first-time visitors to a destination, previous experience positively affects the culinary choice (Youn \& Kim, 2018) as well as having influence over successive visits (Wijaya et al., 2016).

The tasting of specialties can be achieved without having to travel thanks to two reasons: the unstoppable process of globalization makes specialties available anywhere in the world, and in addition, the greater availability of ethnic restaurants in the countries of origin of the tourist gives them the possibility to experience international gastronomy (Seo et al., 2013; Chavarria \& Phakdee-Auksorn, 2017). Both aspects improve the potential knowledge of the tourist even before going to the destination (Mak et al., 2012; Madaleno et al., 2018). In essence, contact with the culinary heritage before and during the visit improves tourists' knowledge and influences the tasting in a positive way (Youn \& Kim, 2018). Third, lack of information on local specialties' characteristics sometimes leads to situations that are harmful to establishments (Kim et al., 2009; Mak et al., 2017; Wu et al., 2016). Sometimes local gastronomy is seen only from the perspective of problems such as hygiene, unknown flavours, and strange ingredients that are an obstacle to enjoyment (Lee \& Scott, 2014; Caber et al., 2018). To avoid this situation, it is important to provide information in various areas.

\section{Personality trait: neophilia}

Experiences related to local gastronomy can provoke a variety of feelings for those who move from unpleasant and uncomfortable reactions to pleasurable and fascinating sensations (Cohen \& Avieli, 2004; Wu et al., 2016). Scholars have found that the tourist is in a continuous search for gratification (Dimitrovski \& Crespi-Vallbona, 2016), and the local culinary heritage provides intense and immediate sensorial stimuli that contribute to the tourist's experience, even to a greater extent than other attractions (Poria et al., 2013). This includes the satisfaction of discovering a new specialty that is not routinely tasted (Madaleno et al., 2018). Those who have a positive intention regarding local 
culinary customs during their visit and value these experiences are tourists of neophilic traits (Kim et al., 2010; Özdemir \& Seyitoğlu, 2017). Establishing a relationship between motivation and personality traits, it is possible to quantify tourists into two large groups: a) those who show a neophobic attitude (rejection) have little or no interest in participating in activities related to gastronomy (including tasting); and b) those who show a neophilic behaviour (acceptance) wish to participate in and enjoy the culinary heritage (Dimitrovskia \& Crespi-Vallbona, 2016; Madaleno et al., 2016; Hsu et al., 2018). In essence, gastronomic tourism as a modality can be considered a maximum experience when, in addition to perceiving local specialties in an authentic way and as a symbol of local culture, there is a receptive and conducive behaviour for tasting (Mak et al., 2017).

In accordance with the literature review, we propose two additional hypotheses:

$\mathrm{H}_{3}$ : Gastronomic motivations and neophilic personality traits are related in a positive way (Mak et al., 2012; Seo et al., 2013; Wang \& Mattila, 2015; Ji et al., 2016; Madaleno et al., 2018; Chen \& Huang, 2018).

$\mathrm{H}_{4}$ : Gastronomic motivations and neophobic personality traits are inversely related (Seo et al., 2013; Wang \& Mattila, 2015; Ji et al., 2016; Madaleno et al., 2016; Muhammad et al., 2016; Choe \& Kim, 2018).

\section{METHODOLOGY}

The methodology used in the present investigation contributes to deepen the knowledge of the culinary profile of the tourist who visits the city of Córdoba as a recognized cultural destination. We analysed two essential factors: culinary motivations and personality traits (neophobia and neophilia) of the individual associated with gastronomy. The field work took place in selected catering establishments that met the following requirements: wide acceptance by tourists visiting the city's Jewish Quarter (and Historic Quarter) and cuisine that reflects the locality. Diners tasted dishes and then were given a questionnaire to complete afterward (allowing for anonymity).

In this context, the survey is an effective data-collection tool that has been used in previous research (Kim et al., 2013; Björk \& Kauppinen-Räisänen, 2016). The survey was conducted between May 2014 and January 2015 and was distributed in four languages (English, French, German, and Spanish). A total of 1,014 valid surveys were obtained, of which 568 corresponded to nationals and 447 to international tourists. A mix of technical issues was examined through a 5-point Likert scale to assess perceptions, along with questions with yes/no answers and others with closed questions. SPSS software v. 23 was used for the statistical analysis of data. Factorial analysis was carried out (analysis of main components) using as reference the culinary motivational dimensions and incorporating the multivariate technique of grouping cases. Essential statistical techniques were applied: Cronbach's alpha statistic, K-means clusters, and analysis of variance (ANOVA) by nonparametric test.

\section{RESULTS \\ Motivations associated with the local cuisine during the stay at the destination}

A factorial analysis of the scale of attributes was performed to identify a small number of explanatory factors for tourists' intentions, resulting in four motivational dimensions related to local gastronomy (Table 2). Although we focus on the factorial scores derived from these components to establish the motivational strength of each visitor, we also need to characterize the four dimensions. Thus, we obtained 18 items to assess the culinary motivation of the destination. As shown in Table 2, the value of the 
sample adequacy of Kaiser-Meyer-Olkin (KMO) was 0.907 and the Bartlett Sphericity Test was 7,614.737 with a significance level equal to 0.000 . Both results indicate the appropriateness of performing factor analysis. For the extraction of dimensions, principal components analysis with varimax rotation was used, assigning which items corresponded to each dimension. The result of four components explained $61.516 \%$ of the total variance. The factorial analysis showed an indirect indicator of the relevance that the different motivational dimensions represented for the respondents.

Table 2. Factorial matrix, rotated components - Culinary motivations in the city of Córdoba -

\begin{tabular}{|c|c|c|c|c|c|}
\hline \multirow{2}{*}{ Motivational aspects } & \multicolumn{4}{|c|}{ Components } & \multirow{2}{*}{$\begin{array}{l}\text { Motivational } \\
\text { dimensions }\end{array}$} \\
\hline & 1 & 2 & 3 & 4 & \\
\hline To learn what this local food tastes like & & 0.532 & & & \multirow{5}{*}{ Cultural } \\
\hline Offers a unique opportunity to understand local culture & & 0.732 & & & \\
\hline To discover something new & & 0.782 & & & \\
\hline To increase my knowledge about different cultures & & 0.748 & & & \\
\hline An authentic experience & & 0.652 & & & \\
\hline Helps me to relax & & & & 0.747 & \multirow{3}{*}{ Emotional } \\
\hline Takes me away from the crowds and noise & & & & 0.783 & \\
\hline Is different from what I normally eat & & & & 0.525 & \\
\hline $\begin{array}{l}\text { Talking to everybody about my local food } \\
\text { experiences }\end{array}$ & & & 0.663 & & \multirow{4}{*}{ Interpersonal } \\
\hline Having local food increases friendship or kinship & & & 0.682 & & \\
\hline $\begin{array}{l}\text { Giving advice about local food experiences to people } \\
\text { who want to travel }\end{array}$ & & & 0.756 & & \\
\hline $\begin{array}{l}\text { Enables me to have an enjoyable time with friends } \\
\text { and/or family }\end{array}$ & & & 0.694 & & \\
\hline Smells nice & 0.677 & & & & \multirow{6}{*}{$\begin{array}{l}\text { Sensory- } \\
\text { Healthy }\end{array}$} \\
\hline Tastes good & 0.681 & & & & \\
\hline Looks nice & 0.744 & & & & \\
\hline Is nutritious & 0.767 & & & & \\
\hline $\begin{array}{l}\text { Contains a lot of fresh ingredients produced in a } \\
\text { local area }\end{array}$ & 0.752 & & & & \\
\hline Keeps me healthy & 0,763 & & & & \\
\hline Eigenvalues & 3.688 & 2.972 & 2.577 & 1.835 & \\
\hline \% variance explained & 20.491 & 16.512 & 14.317 & 10.196 & \\
\hline \% variance cumulative & 20.491 & 37.003 & 51.319 & 61.516 & \\
\hline KMO & \multicolumn{4}{|c|}{0.907} & \\
\hline Bartlett's test of sphericity & \multicolumn{5}{|c|}{ Chi-cuadrado $=7,614.737 \mathrm{sig}<0.001$} \\
\hline
\end{tabular}

In order of importance, the first dimension is called sensory-healthy and is related to the appreciation of the local cuisine for its sensory characteristics (pleasant smell, visual appeal) and for a greater use of fresh and nutritious ingredients, compared to other dishes. The importance of this dimension by itself explained $20.491 \%$ of the total variance of the motivation matrix, with a value of 3.688 .

The second extracted dimension, cultural, forms the most traditional and identifying part of the visited destination, a reflection of the received cultural heritage. 
It had an eigenvalue of 2.972 , describing $16.152 \%$ of the total variance. The third dimension, interpersonal, results from the ability to provide pleasant moments with family and/or friends, reinforcing the bonds of union. It explained $\mathbf{1 4 . 1 3 7 \%}$ of the total variance of the motivation matrix, with a value of 2.577. The last extracted dimension, emotion, is related to the opportunity to relax, differentiated from everyday activities, during the gastronomic experience. It obtained an eigenvalue of 1.835, describing $10.196 \%$ of the total variance. Regarding the reliability of the questionnaire, the Cronbach's alpha coefficient of the final scale of the 18 items had a value of 0.901 , indicative of meritorious internal consistency among elements.

Table 3. Characterization of the segments according to the motivations

\begin{tabular}{|c|c|c|c|c|c|c|c|}
\hline & \multicolumn{4}{|c|}{ Gastronomic clusters } & \multirow{2}{*}{ Average } & \multicolumn{2}{|c|}{ H-Kruskal Wallis } \\
\hline & 1 & 2 & 3 & 4 & & $x^{2}$ & Sig. \\
\hline \multicolumn{8}{|c|}{ Cultural motivation (average) } \\
\hline To learn what this local food tastes like & 2.89 & 4.10 & 4.53 & 4.03 & 2.89 & 214,478 & $<0.000$ \\
\hline $\begin{array}{l}\text { Offers a unique opportunity to understa } \\
\text { local culture }\end{array}$ & 2.11 & 3.88 & 4.06 & 3.87 & 3.63 & 266,569 & $<0.000$ \\
\hline To discover something new & 2.30 & 4.08 & 4.03 & 4.09 & 3.76 & 228,234 & $<0.000$ \\
\hline To increase my knowledge about different cu & 2.37 & 3.97 & 3.87 & 4.05 & .69 & 207,580 & $<0.000$ \\
\hline An authentic experience & 2.08 & 3.47 & 3.65 & 3.98 & 3.46 & 231,183 & $<0.000$ \\
\hline \multicolumn{8}{|c|}{ Emotional motivation (average) } \\
\hline Helps me to relax & 2.11 & 2.39 & 2.28 & 3.92 & 2.84 & 359,377 & $<0.000$ \\
\hline Takes me away from & 1.96 & 1.96 & 1.99 & 3.74 & 2.59 & 403,970 & $<0.000$ \\
\hline hally eat & 2.31 & 2.96 & 3.23 & 3.90 & 3.26 & 169,514 & $<0.000$ \\
\hline \multicolumn{8}{|c|}{ Interpersonal motivation (average) } \\
\hline $\begin{array}{l}\text { Talking to everybody about my loc } \\
\text { experiences }\end{array}$ & 1.89 & 2.27 & 3.25 & 3.48 & 2.92 & 231,959 & $<0.000$ \\
\hline $\begin{array}{l}\text { Having local food increases friendship or } \\
\text { kinship }\end{array}$ & 2.18 & 2.18 & 3.46 & 3.62 & 3.06 & 234,569 & $<0.000$ \\
\hline out local food exp & 2.29 & 2.41 & 3.53 & 3.65 & 3.15 & 192,870 & $<0.000$ \\
\hline n enjoyable time with & 2.66 & 3.09 & 4.11 & 3.94 & 3.61 & 146,396 & $<0.000$ \\
\hline \multicolumn{8}{|c|}{ Sensory-healthy motivation (average) } \\
\hline $\mathrm{Sm}$ & 2.80 & 2.65 & 4.21 & 3.92 & 3.58 & 248,790 & $<0.000$ \\
\hline & 3.26 & 3.31 & 4.55 & 4.08 & 3.93 & 210,024 & $<0.000$ \\
\hline Looks & 3.10 & 2.84 & 4.31 & 4.11 & 3.76 & 227,844 & $<0.000$ \\
\hline Is nu & 2.93 & 2.12 & 3.92 & 3.82 & 39 & \begin{tabular}{|l|}
271,183 \\
\end{tabular} & $<0.000$ \\
\hline $\begin{array}{l}\text { Contains a lot of fresh ingredients produced in } \\
\text { a local area }\end{array}$ & 3.08 & 2.55 & 4.15 & 3.96 & 3.61 & 227,134 & $<0.000$ \\
\hline Keeps me healthy & 3.00 & 2.22 & 4.01 & 3.80 & 3.43 & 258,648 & $<0.000$ \\
\hline
\end{tabular}

This coefficient reaches positive values between $\mathrm{o}$ and 1 , where zero shows total absence of internal consistency, and a total redundancy between the items, providing a valid result. In addition, the critical level (p) associated with Friedman's statistical $\chi^{2}$ $(2,102.152)$ of the analysis tests the null hypothesis (the set of elements of the scale has the same mean is less than 0.001), rejecting the hypothesis that the means of the 
elements are the same. These results confirm the existence of different gastronomic motivational factors during the visit. Thus, $\mathrm{H} 1$ is accepted.

\section{Segmentation of the sample according to gastronomic motivations to visit the destination}

The study of the dimensions carried out provides foundations to establish a segmentation of tourists who visit Córdoba. A non-hierarchical conglomerate analysis was performed with the factorial scores of the four dimensions analysed (sensoryhealthy, cultural, interpersonal, and emotion). In this context, cluster analysis is a multivariate technique that allows grouping the variables based on their similarity .

In maximizing the variance between typologies and minimizing the variance in the set of each typology, the optimal solution that reaffirms the criteria is that which introduces four conglomerates. To this end, test $\mathrm{H}$ of Kruskal-Wallis (1952) was carried out. Unlike the F statistic of the ANOVA does not need to establish the assumptions of normality and equality of variances of the variables for possible groupings (two, three, and four segments), reaffirming that the solution that optimizes the values of the KruskalWallis statistic is in four conglomerates. Table 3 shows the characterization of different clusters from the means of the 18 items considered to measure the culinary motivations of the destination. It must be taken into account that the Kruskal-Wallis statistic II allows to contrast that the averages compared are not equal between different clusters. However, it does not confirm where the observed differences are located.

The incorporation of the Mann-Whitney U statistic (1947) allows us to know which mean differs from another. The first cluster, made up of 168 visitors $17.28 \%$ of the sample), is the least numerous and the one that has the lowest scores in all dimensions. This cluster is called a non-gastronomic tourist, and it can be affirmed that its relationship with the local gastronomy is merely physiological. The second cluster presents significant values in the cultural dimension, noting low values in the rest. These individuals are designated as cultural gastronomic tourists, since the tasting of local dishes is an important vehicle to know and understand the culture of the region visited, according to the scientific literature (López-Guzmán et al., 2017). The cluster ranks second in volume of tourists (178), or $18.31 \%$ of respondents. The third cluster presents significant values in three of the dimensions, reaching a good score in sensorial factor-healthy and cultural, and acceptable in the interpersonal dimension. The cluster is called gastronomic tourist started because culinary motivations are perceived as better and more easily recognized (i.e., cultural and sensory-healthy value traditionally associated with local cuisine); it subtly values the ability to relate to others around a specialty. The third cluster was represented by 287 visitors, or $29.53 \%$ of respondents. The fourth cluster presents significant values in all dimensions and is named full gastronomic tourist, connecting with the set of culinary motivations analysed.

Here, the visitor values the gastronomic heritage as part of the culture of the destination, values the health aspects, and is also in search of new experiences that meet social and interpersonal needs. This is the most important cluster in number of tourists (339), representing 34.88\% of respondents. To verify the correctness of the segmentation, tourists were questioned about the importance of gastronomy as a general reason for the visit to Córdoba. In the subsequent analysis, statistically significant differences were observed between the segments (statistical H of Kruskal-Wallis = 82,157, $\mathrm{p}=0.000$ ).

The gamma coefficient showed a direct relationship between gastronomy as the main reason to visit the city and the gastronomic tourist (cluster 4$)(0.376, p=0.000)$. The Mann-Whitney statistic was used to establish the differences between segments. Since the critical level associated with both statistics was less than 0.05, the null hypothesis was 
rejected. In addition, the difference in the medians of the populations was statistically significant for the set of dimensions. The results were validated through a discriminant analysis to determine what percentage of the sample was correctly assigned. The result indicated validity (95.1\% of tourists correctly assigned). However, of the total number of individuals (339) in the full culinary cluster, there are four that the analysis locates in the non-gastronomic cluster, six in the cultural gastronomic and three in the gastronomic started cluster. In short, the set of dimensions presented differences between clusters, showing that those tourists with greater interest in local gastronomic tasting reached higher values in the four motivational dimensions analysed. Therefore $\mathrm{H} 2$ is accepted.

\section{neophilia}

Personality traits associated with gastronomy: neophobia and

The construction of a local tasting model implies the integration of internal constructs. In this context, personality traits related to gastronomy were measured with a 5-point Likert scale ( 1 = very little satisfied, 5 = very satisfied).

Regarding the different personality traits of the respondents, a total of 11 items were selected to determine the relative importance of a series of reasons that influenced their decision to taste local ingredients and dishes. The items were grouped into two dimensions: neophilia (favourable attitude to taste the local cuisine) and neophobia (rejection of it). The six items of neophilia presented meritorious internal consistency, with a Cronbach's alpha of 0.815 . In addition, the critical level (p) associated with Friedman's statistical $\chi^{2} 406,556$ was less than 0.001 , showing that the means of the elements were not equal. For questions related to neophobia, the items were tabulated by considering that the relevant aspects had a lower score. The five items of neophobia presented meritorious internal consistency, with a Cronbach's alpha of 0.775 .

In this case, the critical level (p) associated with Friedman's statistical $\chi^{2}$ 90,067 was less than 0.001, showing that the means of the elements were not equal. The neophilia dimension had an average value of 3.73. The best rated items were "I like trying new ethnic restaurants" and "When I travel I'm excited to try local food". The neophobia dimension had an average score of 2.46. "I am afraid to eat things I have never had before" and "If I do not know what food is, I'm not going to try it" were highlighted items.

Table 4. Analysis of personality traits in segments

\begin{tabular}{|l|c|c|c|c|c|c|}
\hline \multirow{2}{*}{$\begin{array}{l}\text { Personality } \\
\text { dimensions }\end{array}$} & \multicolumn{4}{|c|}{ Gastronomic segments } & \multicolumn{2}{c|}{$\begin{array}{c}\text { H-Kruskal } \\
\text { Wallis }\end{array}$} \\
\cline { 2 - 7 } & $\begin{array}{c}\text { Non- } \\
\text { gastronomic }\end{array}$ & Cultural & $\begin{array}{c}\text { Gastronomic } \\
\text { started }\end{array}$ & Full & $\chi^{\mathbf{2}}$ & Sig. \\
\hline Neophilia & $3.06^{(*)}$ & $3.63^{(*)}$ & 3.92 & 3.90 & 105.584 & $<0.000$ \\
\hline Neophobia & 2.50 & 2.19 & 2.33 & 2.66 & 31.260 & $<0.000$ \\
\hline $\begin{array}{l}(*) \text { Values in bold present significant differences in three out of four of the means clusters. The U-Mann- } \\
\text { Whitney test was applied to test for significant differences between the different means }\end{array}$ \\
\hline
\end{tabular}

The analysis by clusters allows us to contrast the existence of significant differences for each of the personality dimensions. The segments with the highest culinary value (gastronomic tourist started) recorded the highest values in the neophilia dimension, reinforcing the intention to taste local specialties. The cultural cluster presented acceptable values, while the non-gastronomic cluster registered the lowest levels of the dimension, implying that it is not related to this personality trait. The gamma coefficient revealed the existence of a significant and direct relationship between neophilic and full gastronomic tourists $(0.266, \mathrm{p}=0.000)$. With these results, $\mathrm{H}_{3}$ is accepted. Table 4 
shows the different clusters and dimensions associated with the personality traits. Regarding the neophobia dimension, the assessments were low for the four groups, indicating that there were no significant levels. Therefore, $\mathrm{H}_{4}$ is rejected.

\section{CONCLUSION}

The analysis allowed the identification of four dimensions depending on gastronomic motivation: sensory-healthy, emotion, interpersonal, and cultural. Based on these, four segmenting typologies were established and validated: non-gastronomic tourist, cultural gastronomic tourist, gastronomic tourist started, and full gastronomic tourist. The non-gastronomic tourist has little relation with any gastronomic dimension. The cultural gastronomic tourist obtains high scores in items related to the cultural dimension. The gastronomic tourist started achieves the highest scores in the items related to the cultural and sensory-healthy dimension (most recognized aspects of gastronomy). Finally, the full gastronomic tourist presents the highest values in all items (sensory-healthy, cultural, emotion, and interpersonal). In short, this tourist values the aspects associated with local gastronomy as well as the use of fresh ingredients, how they reflect part of the culture of the city, and the opportunity to socialize and enjoy the tranquillity that the environment provides. In short, tourists can be classified significantly depending on their interest in local cuisine. Once the clusters were designated, other internal constructs (personality traits) were incorporated. The gastronomic motivations and the personality traits are related. Thus, tourists with high gastronomic motivation have neophilic features (favourable attitude to taste unknown ingredients and dishes). It is not possible to confirm that individuals with less gastronomic motivation possess greater neophobic traits (refusal to taste local gastronomy). The main practical application of this research was to take a step further in the knowledge of tourism demand, expectations, and preferences in order to design products and services and strategies that best meet their needs. Córdoba is integrated into a region endowed with resources and tourist attractions, so that public administrations and the local business community must bet firmly on this sector to provide for socioeconomic development of a city that needs to raise the levels of employment and consolidate the well-being of its citizens. The city needs to integrate quality tourism (such as that which represents the gastronomic field) and be respectful of the architectural heritage and local customs, in a climate of absolute coexistence. Two recommendations should be highlighted:

- Take advantage of the good image of the local culinary heritage to promote and consolidate the city of Córdoba as a cultural destination. In addition, take advantage of the complementarity that gastronomy, as a resource, offers with other projects. In this context, it is possible to explore the feasibility of new proposals that relate restoration with other elements of local culture, such as archaeology or architectural heritage. In other words, investigate the transversal possibilities that gastronomy offers in the tourist context.

- To boost the local and regional economy, the cooperation of all responsible actors should be channelled, relating to the effective implementation of gastronomic offerings of the city as well as to effective marketing of a brand image.

Because the main limitation of this investigation is that it represented a short duration, it would be helpful to extend the research to full-year tourism in the city. This empirical research applied a combination of theory and practice to the gastronomic field in an attempt to understand the tourism context in Córdoba.

Based on the results, it is possible to identify lines of action and recommendations to be considered for the consolidation of this sector. One proposal is to make a comparison between national and international tourists in an attempt to analyse the motivations of the different segments according to their origin, in order to better understand the demand of tourists who opt for this destination. 


\section{REFERENCES}

Akdag, G., Guler, O., Dalgic, A., Sercan, B., \& Cakici, A. C. (2018). Do tourists' gastronomic experiences differ within the same geographical region? A comparative study of two Mediterranean destinations. British Food Journal, no. 120, vol. 1, p. 158-171.

Antón, C., Camarero, C., \& Laguna-García, M. (2017). Towards a new approach of destination royalty drivers: Satisfaction, visit intensity and tourist motivation. Current Issues in Tourism, no. 20, vol.3, p. 238-260.

Björk, P., \& Kauppinen-Räisänen, H. (2016). Local food: A source for destination attraction. International Journal of Contemporary Hospitality Management, no. 28, vol. 1, p. 177-194.

Caber, M., Yilmaz, G., Kiliçarslan, D., \& Öztürk, A. (2018). The effects of tour guide performance and food involvement on food neophobia and local food consumption intention. International Journal of Contemporary Hospitality Management, no. 30, vol.3, p. 1472-1491.

Chavarria, L. C. T., \& Phakdee-auksorn, P. (2017). Understanding international tourists' attitudes towards street food in Phuket, Thailand. Tourism Management Perspectives, no. 21, p. 66-73.

Chen, Q., \& Huang, R. (2018). Understanding the role of local food in sustaining Chinese destinations. Current Issues in Tourism, no. 22, vol. 5, 544-560.

Choe, J. Y. J., \& Kim, S. S. (2018). Effects of tourists' local food consumption value on attitude, food destination image, and behavioral intention. International Journal of Hospitality Management, no. 71, p. 1-10.

Cohen, E., \& Avieli, N. (2004). Food in tourism: Attraction and impediment. Annals of Tourism Research, no. 31 , vol. 4 , p. $755-778$.

Crompton, J. L. (1979). Motivations for pleasure vacation. Annals of Tourism Research 6 (4): 408-424.

Dimitrovski, D., \& Crespi-Vallbona, M. (2016). Role of food neophilia in food market tourists' motivational construct: The case of La Boqueria in Barcelona, Spain. Journal of Travel \&Tourism Marketing, no. 34, vol. 4 , p. $475-487$.

Fields, K. (2002). Demand for the gastronomy tourism product: Motivational factors. In Tourism and Gastronomy. Edited by Hjalager, A. M., and Richards, G. London: Routledge, pp. 36-50.

Frisvoll, S., Forbord, M., \& Blekesaune, A. (2016). An empirical investigation of tourists' consumption of local food in rural tourism. Scandinavian Journal of Hospitality and Tourism, no. 16, vol. 1, p. 76-93.

Goolaup, S., \& Mossberg, L. (2017). Exploring the concept of extraordinary related to food tourists' nature-based experience. Scandinavian Journal of Hospitality and Tourism, no. 17, p. 27-43.

Hanks, L., Zhang, L., \& McGinley, S. (2016). Unconditioned superstition and sports bar fans. Journal of Hospitality Marketing \& Management, no. 25, vol. 1, p. 113-131.

Hsu, F. C., Robinson, R. N. S., \& Scott, N. (2018). Traditional food consumption behaviour: The case of Taiwan. Tourism Recreation Research, no. 43, vol. 4, p. 456-469.

Huang, J. (2017). The dining experience of Beijing Roast Duck: A comparative study of the Chinese and English online consumer reviews. International Journal of Hospitality Management 66: 117-129.

Jang, S. S., \& Kim, D. (2015). Enhancing ethnic food acceptance and reducing perceived risk: The effects of personality traits, cultural familiarity, and menu framing. International Journal of Hospitality Management, no. 47, p. 85-95.

Ji, M., Wong, I. A., Eves, A., \& Scarles, C. (2016). Food-related personality traits and the moderating role of novelty-seeking in food satisfaction and travel outcomes. Tourism Management, no. 57, p. 387-396.

Kim, Y. G., Eves, A., \& Scarles, C. (2009). Building a model of local food consumption on trips and holidays: A grounded theory approach. International Journal of Hospitality Management, no. 28, vol. 3, p. 423-431.

Kim, Y. G., Eves, A., \& Scarles, C. (2013). Empirical verification of a conceptual model of local food consumption at a tourist destination. International Journal of Hospitality Management, no. 33, p. 484-489.

Kim, Y. G., \& Eves, A. (2014). Measurement Equivalence of an Instrument Measuring Motivation to Consume Local Food: A Cross-Cultural Examination Across British and Korean. Journal of Hospitality \& Tourism Research, no. 40, vol. 5, p. 634-652.

Kim, A. K. J., \& Kim, Y. G. (2017). Understanding ethnic food involvement-based markets and their travel preferences. Anatolia, no. 28, vol. 2, p. 182-196.

Kim, Y. G., Suh, B. W., \& Eves, A. (2010). The relationships between food-related personality traits, satisfaction, and loyalty among visitors attending food events and festivals. International Journal of Hospitality Management, no. 29, p. 216-226.

Lee, K.-H., \& Scott, N. (2014). Food tourism reviewed using the paradigm funnel approach. Journal of Culinary Science \& Technology, no. 13, vol. 2, p. 95-115.

Lin, Y.-C. \& Chen, C.-C. (2014). Needs assessment for food and food services and behavioral intention of Chinese group tourists who visited Taiwan. Asia Pacific Journal of Tourism Research, no. 19, vol. 1, p. 1-16.

López-Guzmán, T., Pérez-Gálvez, J. C. \& Muñoz-Fernández, G. A. (2019). A quality-of-life perspective of tourists in traditional wine festivals: The case of the wine-tasting festival in Córdoba, Spain. In Best Practices in Hospitality and Tourism Marketing and Management, pp. 297-311. Cham: Springer.

López-Guzmán, T., Torres Naranjo, M., Pérez Gálvez, J. C., \& Carvache Franco, W. (2017). Segmentation and motivation of foreign tourists in world heritage sites. A case study, Quito (Ecuador). Current Issues in Tourism, p. 1-20.

López-Guzmán T., Torres Naranjo M., Pérez- Gálvez J.C., \& Carvache Franco W. (2018). Gastronomic Perception and Motivation of a Touristic Destination: The City of Quito, Ecuador. GeoJournal of Tourism and Geosites, Year XI, no. 1, vol. 21, p.61-73

Madaleno, A., Eusébio, C., \& Varum, C. (2016). International tourism and exports of agro-food products: A causality analysis. Anatolia, no. 27, vol. 2, p. 251-261.

Madaleno, A., Eusébio, C., \& Varum, C. (2018). Purchase of local food products during trips by international visitors. International Journal of Tourism Research, no. 20, vol. 1, p. 115-125. 


\section{Javier JIMÉNEZ-BELTRÁN, Carol JARA-ALBA, Jaime ROLDAN NOGUERAS, Gema GOMEZ-CASERO}

Maeng, H. Y., Jang, H. Y., \& Li, J. M. (2016). A critical review of the motivational factors for festival attendance based on meta-analysis. Journal in Tourism Management Perspective, no. 17, p. 16-25.

Mak, A. H. N., Lumbers, M., Eves, A., \& Chang, R. C. Y. (2012). Factors influencing tourist food consumption. International Journal of Hospitality Management, no. 31, vol. 3, p. 928-936.

Mak, A. H. N., Lumbers, M., Eves, A., \& Chang, R. C. Y. (2013). An application of the repertory grid method and generalised Procrustes analysis to investigate the motivational factors of tourist food consumption. International Journal of Hospitality Management, no. 35, p. 327-338.

Mak, A. H. N., Lumbers, M., Eves, A., \& Chang, R. C. Y. (2017). The effects of food-related personality traits on tourist food consumption motivations. Asia Pacific Journal of Tourism Research, no. 22, vol. 1, p. 1-20.

Matlovičová K., Kolesárová J. \& Matlovič R. (2014). The use and stimulation of culinary tourism in learning about local and regional cultural peculiarities and historical heritage. In Faracik R., Widawski K. (Eds), 2014. Enhancing competitiveness of V4 historic cities to develop tourism. Aspects of cultural heritage. Krakow, Center-Print Kft., p. 141-164.

Matlovičová K. \& Pompura M. (2013). The Culinary Tourism in Slovakia Case Study of the Traditional Local Sheep's Milk Products in the regions of Orava and Liptov. GeoJournal of Tourism and Geosites, Year VI, no. 2, vol. 12, p. 129-144.

Muhammad, R., Ibrahim, M. A., Ahmad, R., \& Hanan, F. (2016). Psychological factors on food neophobia among the young culinarian in Malaysia: Novel food preferences. Procedia - Social and Behavioral Sciences, no. 222, p. 358-366.

Mynttinen, S., Logrén, J. Särkkä-Tirkkonen, M., \& Rautiainen, T. (2015). Perceptions of food and its locality among Russian tourists in the South Savo region of Finland. Tourism Management, no. 48, p. 455-466.

Oh, M. M., Chan, I. C. C., \& Mehraliyev, F. (2018). Ethnic restaurant selection patterns of US tourists in Hong Kong: An application of association rule mining. In Information and Communication Technologies in Tourism, pp. 117-128. Cham: Springer.

Özdemir, B., \& Seyitoğlu, F. (2017). A conceptual study of gastronomical quests of tourists: Authenticity or safety and comfort? Tourism Management Perspectives, no. 23, p. 1-7.

Privitera D., Nedelcu A., Nicula V. (2018). Gastronomic and food tourism as an economic local resource: case studies from Romania and Italy. GeoJournal of Tourism and Geosites, Year XXII, no. 1, vol. 21, p. $143-157$.

Poria, Y., Reichel, A., \& Cohen, R. (2013). Tourists' perceptions of World Heritage Site and its designation. Tourism Management, no. 35, p. 272-274.

Seo, S., Kim, O. Y., Oh, S., \& Yun, N. (2013). Influence of informational and experiential familiarity on image of local foods. International Journal of Hospitality Management, no. 34, p. 295-308.

Seo, S., \& Yun, N. (2015). Multi-dimensional scale to measure destination food image: Case of Korean food. British Food Journal, no. 117, vol. 12, p. 2914-2929.

Son, A., \& Xu, H. (2013). Religious food as a tourism attraction: The roles of Buddhist temple food in Western tourist experience. Journal of Heritage Tourism, no. 8, vol. 2-3, p. 248-258.

Sthapit, E. (2017). Exploring tourists' memorable food experiences: A study of visitors to Santa's official hometown. Anatolia, no. 28, vol. 3, p. 404-421.

Sthapit, E., Björk, P., \& Coudounaris, D. N. (2017). Emotions elicited by local food consumption, memories, place attachment and behavioural intentions. Anatolia, no. 28, vol. 3, p. 363-380.

Tanford, S., \& Jung, S. (2017). Festival attributes and perceptions: A meta-analysis of relationships with satisfaction and loyalty. Tourism Management, no. 61, p. 209-220.

Ting, H., Tan, S., \& John, A. N. (2017). Consumption intention towards ethnic food: Determinants of dayak food choice by Malaysians. Journal of Ethnic Foods, no. 4, vol. 1, p. 21-27.

Wang, C. Y., \& Mattila, A. S. (2015). The impact of servicescape cuestion consumer prepurchase authenticity assessment and patronage intentions to ethnic restaurants. Journal of Hospitality \& Tourism Research, no. 39, vol. 3, p. 346-372.

Wijaya, S., Morrison, A., Nguyen, T., \& King, B. (2016). Exploration of culinary tourism in Indonesia: What do the international visitors expect? Asia Tourism Forum 2016 - The 12th Biennial Conference of Hospitality and Tourism Industry in Asia (ATF-16), 374-379.

Wu, K., Raab, C., Chang, W., \& Krishen, A. (2016). Understanding Chinese tourists' food consumption in the United States. Journal of Business Research, no. 69, vol. 10, p. 4706-4713.

$\mathrm{Xu}$, Y. H., \& Zhang, Y. G. (2016). Explaining the consumer behaviors of culinary event attendees: From event motivation to event behavioral intentions. CAUTHE 2016: The Changing Landscape of Tourism and Hospitality: The Impact of Emerging Markets and Emerging Destinations. Sydney: Blue Mountains International Hotel Management School 562-578.

Youn, H., \& Kim, J. (2018). Is unfamiliarity a double-edged sword for ethnic restaurants? International Journal of Hospitality Management, no. 68, p. 23-31.

Yusuf, M. (2017). Measuring tourists' motivations for consuming local Angkringan street food in Yogyakarta, Indonesia. Journal of Indonesian Tourism and Development Studies, no. 5, vol. 2, p. 65-72

*** World Tourism Organization, WTO. (2012). Global report on Food Tourism. Madrid. OMT publicaciones.

Submitted:

25.03.2019
Revised:

30.09.2019
Accepted and published online

03.10.2019 